\title{
STRATEGI PENAYANGAN ACARA TELEVISI TERHADAP PENDIDIKAN ANAK DAN REMAJA
}

Tri Weìe Raharjo

\section{ABSTRAK}

7 Wiuan kajian ini adalah mengetahni (a) penganuh media massa ki.ususnya teievisi

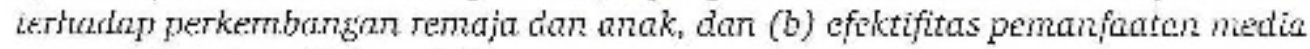
massa sebagai media pendidikan.

Kesimpalan yarg merggunakan SWOT Analysis ini adizlah (a) penganh media massa khususnya relevisi sangar besar lerhadap perkembargan remaja dan anak, baik secara

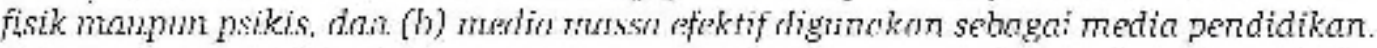
Adapun Saran adalah: (a) orang tua agar memberikn pengertimn anak-anaknya ketika menonton televisi, senta mencarikan alternatif kegralan, sehwigga arak cinat meiupakan

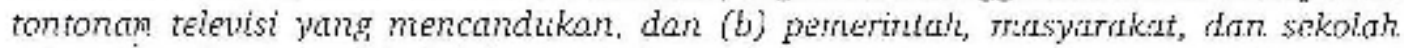
sehamusina berperan akifi dalam memberikan sumbangan pada media massa tentang pendidikan.

Kata. Kunai : Acara Televisi, Pendidikan Arak dan Remaja.

\section{PENDAHULUAN}

Perkembangan rekiologi inlonmasi dan transportasi secara, pesat telah mendorong terbangunnya jaringan iatormasi dan cransportasi dunia, schingga memperpendek jarak antar wilayah. Tidak salah jika McLuhan menycjutkan bahwa dunia saat ini sebagai "global village" (Gudykunst,1992:3).

Perkembangan teknologi informasi inipun lanyak nemberikan liont-ibusj yang, berarti bagi perkembangan media massa. Di bidang media cetak misalnya, pada tahun 1990an di provinsi-provinsi tertentu di Indonesia seperti lapula unluk bisi mendapalkan surat kabar harian tertertu harus mienunggu sore hari, karena harus diangkı: dengan pesawat udara untuk mencapai daerah tersebut. Dengan adanya teknologi teleprint, maka pada pagi hari, masyarakat di provinsi tersebut sudah bisa membaca suial kabar yang diinginkannya.

Saat ini, media massa utamanya media cetak maupun media elcktronik merupakan media yang banyak digumakan olelı masyarakat ci berbaģai lapisan sosial. Media massa sering digunakan sebugai alat mentransformasikan informosi. Peran media massa, utamartya radio dan televisi juga memiliki keis-imewain dalam hal iuasnya coverage untuk menjanglat lhalayak hingga di pelosok desa hahkan di kaki gunung sekalipun.

Penyiaran sebagai kegiatan komunikasi massa mempunyai fungsi sebagai media informasi, sendidikan, hiburan yang sehat, kontrol dan perckat sosial (UU No.32 Tahum 2002). Fungsi pendidikan dari media massa misalnya 
peruah dilakukan oleh Ratio Republik Indoncsia (RRT) maupur! Televisi Republik Indonesia (TVRl) di tahun delapen puluhan dengan acara "Siaran Pedesaar" yang menjadi media pendidikas masyarakat tani di peciesan. Secara khusus bahkan sampai saat ini kita telah memiliki Televisi Fendicikan Indonesia (TPI).

Pendidikan merupakan suatu bidans yark bermakna luas, dimara pendjdikan meryangkut keseluruban proses Fembentukan perilaku din pola kẻidupan Masyarakia pada umummya. Jika dikaitian dengan kegiatżn media massa, sebenamya apa yang ditayangka: oleh media massa, scbesar apapun pasti mengandung unsur pendidikan di dalamnya.

Jika mcmpcrhatikan fungsi komunikas massa sebagaimana temaktub pada UU No.32 Takun 2002 di atas, kila alkan memjertanyakan sejauhmana fungsi media maşa bisa memberikan kontribusi terhadap pendidikan acau sebaliknya jusıru memiliki dampak yang buruk terhadap pendidikan kila.

\section{PFRMASALAHAN}

Rerdasarkan latar belakang tersebut masalah yang dikaji meliputi :

1. Bagaimana pengarua media massa khususnya televisi rerhadap pe:kembangan anak?

2. Fagcimana arienlasi pengelola media

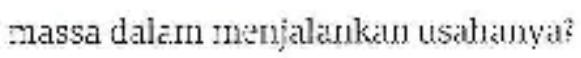

3. Bisgimiman efektivitas pemanfaatan modia massa sebrägai msecila pendidikan?

\section{PEMBAMASAN}

\section{MEDIA MASSA, KOMUNIKASI DAN PRNTMTKAN}

Media massa merupakan salal: satu media yang digunakan untuk melakukan komunikasi anlara dua pihısk, lsaik yengirins maupun penerima informasi. Televisi disamping memiliki keunggulan dengan coverage ‘dalya jangkau) yaug luas juga merupakian perpadian antara media aud:o dan visual. Sehingga pemiliban media televisi dalam kajiar. ini lebih dikarenakan keungsulan tersebul.

Saat ini di Inconesia terdapat leb:h 5) stasiun televisi baik nasional maupin televisi losal, yang semuanya merupakîn televisi yang tidak dinancang secara khusus sebagai televisi untuk tujuar tertcntu misalnya untuk tujuan ponditikar (by ufitities), dan televisi juilah yang diakses oleh masyarakat dengan tujuan untuk memperolch hiburan dz.ri acara tcicvisi ini.

Anak-anak dan remaja yarg memoutun dcara leleyisi ini, tidak senantiasa didamping orangtua mereka, untuk membimbing dan mengarabkan acara mana yang bolelı dan ticak boleh dirorton olch mereka. Sehingg; tentu herdampak tcrhadaj pe:kemhangan psikologi mereka.

Haroid D. Lasswell dalam IJenis (1993:13) berpendapat bahwa cara yang tepat untuk menerangkan suatu kegialar: komunikas: jalah menjawab perlanyaanpertanyaen: "who?" (comtiuunicaior), "Siny What?" (message), "In which chamei?" (Tredinm,", "Tis mhom? (receivei), dan "With ublat effect?" (effect). Konunikasi mernunkan 
suatu aktifitas yang mencerminkan siapa, menyzrmaikan apa, dengan saluran apa, siapa yang menerina, dan apa penganunya.

Model Lesswill ini me:upalan suatu motel yang sangat linice atau satu arah. Sehingga dalam bidang pendidikan suatu pesan permbelajazan (mäleri pelajaran) yang disampaikan kepada peserta didik (pelajar) bersifat searah, dimana sumoèr belajar menucj:kkan suatu aktifitas yang dominan dibanding dengan peajar.

Sebagat suatu model yang bersifat sangat lnier: mendapatkan kritikan sebagai refleksi kelematan formula Lizmwell. Untuk menyempurnakinnya, para pengkut Lasswell (Neo Lasswellian) kemudian menambahkan kalimat "Siapa yang menjawab kepada mereka yang terbicara kepadanya". [ Jengan cemikian, model komunikasi ini menjadi bersizar sirkuter.

Mencermati unsur-ursur komuisikasi terselyut, lerutama jika dimak:ai bahwa unsu: i:u merupakan suatu kesatuan yang utth. maka komunikasi mcrupakan suatu alstifitas yang sengaja dilakbanakan untuk mewujtolkan suatu kehendak atau tujuan sebagai hasil a:au etek dari suatu prozes krmmikasi, dimana tujuan terscbut harus tampak jelas perwujudannya alau keterukurannyc.

Scbagai suatu proses yang bertujuan. Miller (1.9\%6) memberikan penekanan bahwa komumikasi pada dasar ya merupakan peryampaian pesan yang disengaija dari sumher terhadap penerima dengan tujuan mempengaruhi tingkah läku pihak penterima iseniaya; 1941:21).

'Sejaldu tengan itu Evcrett M. Rogers
[-983:5] memberikan definis: bahwa knmunikasi adalide sliatu proses dimana partisipan menciptakan dan membcoi informasi dengan yang lainnya untuk mencapai pengemian bersand. Dengan demilcian, tujuan komunikasi adalah mempengaruhi daiam hal ini mengubah lingkalı laku penerima melalui pemberian serangkaian informasi daxi sumber.

Lalam kaitannya komumikasi scbal,ai proses mempengeruhi dan recroguah tirgkah laku penerima, menunjukkan bahwa komunikasi juga r:erupakan proses atau fonomend stimulirespon sebagai relleksi suatu pengaruk. Dalam hal ini, pengaruh terhatlap tingk.sh laku tampak schagai akrifitas me:espon terhadap stimuli. Kondisi terciptanya aktifitas saling merespon, akan semakin dinamis proses komunikasinya. Astifitas stimuli-respon sebagai pelw:ijudan interaksi antara pemberi (sumber) dan penerima. Dengan demikian, dapar dikatakan bahwa cinggi-rendahnya inceraksi merupakar: cerminan keberhasilan a:au ejoktifnya komunikasi.

Sclanjutrya, meręuai pendidika: scperti ha'.nya kom_nikasi, memiliki banyak z.spek dan sifataya sangat knmplek. Hal ini dikarenakan obyexnya adalar. manus:a. Umar Tir.uraharja (2000:33) menjelaskan bahwa perbedaan batasan-betasari pendidikan karena oricntasinya, kuns\%p dasar yang digunakan, aspek yang menjad: tekanar, atau karena falsafah yang melandașinya. Bebcrapa batasan pendidikar? yang berbeda berdasarlian fungsinya, yaitu: - rend:dikan scbagai suatu proses 
transformasi budaya, "Pendidikan addakah kegiatan pewarisan budaya dari suatu generasi ke generasi yang lain".

- l'endidikan sebagai proses pemherinkn pribadi, "Pendidikan dialah suatu kegiatan yang sistematis dan sistemik terarah kepada terbentuknya kepribadian peserta didik". Pembentukan pribadi meliputi pembenukarr cipta, rasa dan karsa.

- Pendidikan sebagiji proses peryiapan warga Ngara, "Pendidikan adalah suatı kegiata? yang terencana untuk membekali peserta did k agar menjadi warga negara yang baik".

- Pandidikan sebagai penyiapar tenaga kirrja, "Pendid:kan adalah kegiatan membimbi2g pescrta didik. schingga memiliki bekal disasar untuk bekerja".

Jika dicermati batasan tersebut dj atas. nanpaknya bahwa sekalipun be-beda secara redaksiona: karera lujuan dar. fungsinya, ramu: k kpet kita tomukan adanya sualu kesamaan bahwa proses pendidikan memiliki beberapa unsur pentirg, yaitu:

- izeiluimar, bahwa proses pendidikan dilaksa:lakan uintuk mew ujudkan suatu harapan-harapan tertentu, Harapan crscbul selanjutnya mengarahikan jusses pendidikan hingga berhasil mewujudkarnya.

- Direncanakari, bahwa keseluruhan proses pendidikan dilaksanakan secara sçıgaja clan terencana untak Inewujudkan tụjuan pendidikên.

- Sistemik, bahiwa proses pendidikan melibatkan sejumiah unsur dalam pelaksanaannya, dimena keseiuruhan unsur lerscbut merupakan suaru kesatuan yang integral.

- Berproses, babwa pendidikan merupakin keģatan yang berlangsung secal a terus. mencrus, sistematis, berkesinambungan.

Crow and Crow (1988:4-5) memberikan batasan tentang pendidikan sebiagai suatu proses individu dail proses sosiai. Pendidikan bagi tiap individu litafsirkau sebagai sualu proses pengalaman be aịas. Jadi, pendidikan adilah perģalamın yang memberikan pengertian, pandangan, dan penyesuaian bagi scseorang yong menyebabken dia berkembang. Seciangkan scbagai suntu proses sosial, pendicilkan merupakan suatu proses dimanil seseorang dipcagaruhi oleh lingkungan yang teilimpun (misalnya sekolan), selhingga ia dapat mencapai kecakirnn sosial dan mengerabangkdı pribadinya.

Dalicm Undang-undand No.20 Tisun 2003 tentang Sistem Pendidikan Nasiona!, disabutkan bahwa pendicilkan acajah ussha sacar dian terencana untuk mewujuckan suasona belajar agar peserta didik secar: aktif mengembangkan potensi tirinya untuk memiljki kexuatan spiritual kcagamaan, pengendaliar diri, kepribadian, kecerdasan, akhlak mulia, scrta keterampilan yang diperlukan dirinyo, masyarakal, bangsa dan nenara.

Dari batcsan batasan pengertian tantang pendidikan, dapat disimpulkan batwa pendidikan merupakan :satu usaha yang secara sengaja dilaksanakan, sis:emik, sislematis, terorgarisir, untuk mencapai 
tujuan pendicikan. Selanjutnya tujuan pendidikan berbcda-beda dan melahirkan bentuk dan jenis pendidikan.

Dalam keseluruhan proses pendidikal., komunikasi menjadi penling dan utama. Salomon (1981:35) berpendapat baiswa tidak ada tujuan pendidikan yang dapat dicapai lampa adanya komunikasi . Olch karenanya, kornunikasi harus terjadi supaya terwujud proses pendidikan.

Ienditlikan merupakan suam bidaug yang bermakra luas, dimana pendidikan bukan hanya sckolah atau lembaga pendidikan tertertu yang terkaił dengan masalah pembeijajaran, tetaji me:zyangkut keselivuban proses pembentukar: perilaku daz pola ketiriupan masyar'akal Irada umumnya. Karenanyia, Kick \& Gustafson dalam Barbara (1594:1) membediakn cakupan antara pendidikan dan punbeliajaran, di mana pendidik -in mencalkup sel:muh aspek perdidikan ilu serdiri, dan pembelajaran mencakup masalah pengajaran dan masalah belaja:. Perubclajaran adalah subsct dari pendidikan (Serijadi, 1986:3 dan 93).

Pemilikan anak dan remaja sebagai obyck kajian dalam melihat peran media televisi cerhadap peni:.gkatan kualitas peìdilikan lebih dikarenakan perkembangan psikologis anak dan remaja masih rentan dengan pemubahan karena pengaruh luar, bahwa dìlam rentang limkt masa kanak-kanlak (prenalal, masa bayj tan lalih, masa kanakkarak pertama, masa kaulak-kanak kedud dan masa remaja], pribadj dan sikap seseozing dibentuk (Akbür, 2001).

\section{Realita di Lapangan}

Pesan dalam media massa sangat te:letak pada keterampilan pengclolaan informasi yang dikembangzan dan digerakkan oleh tcknolog: dengan berbagaj bentuk dan kodenya. Tampilan gambar pada televisi bersifal visual dan dapal digerakkan oleh teknologi, sehingga dengan mudah dapat disesuaikitr dengan kcinginan.

Kemajuar budaya yang sangat pesat ditandai dengan hadimya muedia massa pada cra informasi di lengah-tengah masyarakat. Intuk memperoleh informasi dan hiburan masyarakat dapat memilih media massa yang disckai baik televisi, radio, video game, surat kabar, computer din scbagainya. Namun demikian, kebutuh:an masyarakat akan incormasi dan hiburan yang sarat dengan perdiclikan kurang rerpexuhi olch berbagai media massa yang adia. Sebagai ccatoh, acara lelevisi yang disaịixan süngat sedikit porsi unluk pendidikan, tetapi lëbih mempriorilaskan segi mnung rugi dari setiap penayangannya.

Di samping ilu, kurang memperhatikan dàmpak yang célah dicayangkan bagi perkembangan anak, kh.ısusnya khayalan-khayalan yang merasuk pada setiap pemirsa. Jika diperhatikan sesumggunna dalam kenyalaan terdapat kecenderungu bahwa penonton ul:visi telah ditominasi oleh anak-anak remaja yang justru banyak terkena dampak siara: lelevisi tcrsebut (Kresno, 2002);

Keumggulan media lelevisi jika dilandingkian dengan media lain: 
a. Mudah masuk ke sasaran pemirsa, sehingga dapat dengan mudah mempengenuhi perilaku manusia;

b. Lebila menarik dari segi hibüln, karena diolah deugan teknolugi yang canggir:

c. Memiliki daya jangkau yang luas;

d. Dapat memberikan informasi yang aklual dalam tempo yang bersamaan da: cepat;

e. Memiliki dunia bisnis;

f. L.ehih murah dalam hal pembiayaan, dan lain-lain (Handoyo, 1997).

Sebagai media massa, televisi seharusnya mampu melaksanakan fungsifungsi sebagai berikut:

i. Mclakukan seleksi, evaluasi, dan interpretasi terhadap informasi \{televisi hatus meiakukan seleksi mengenai apa yang perlu dan pantas untuk ditayangkan):

f. S: Sibegai sarana untuk menyampaikan nilai budaya clari saru generasi ke generas: berikutnya;

c. Sebagai media hiburan, televisi sesuai fungsinya itu, orang akan menyaksikannya. (Schram, 1975).

Sampai saat ini, stasiun televisi yang ada di Indonesia sangal sedikit menunjukkar tingkat kepedulian yang serius ter:thidèp pendicikên anak dalam layangan siaran-siarannya. Walaupun begitu, pernah dalam sejarab pertelivisian Indoncsia ada stasitu televisi yang mengkhususkan diri dalam bidang pendidikan, yairu Televisi Penciidikan Indonesia (TPI).
Pertanyaan yang muncul adalah mengapa stasion televisi yang perannya sangat strategis tersebut, tidak berusaha mengoptimalkan perannya sebagai media pendidiken? Hal tcrsebut tampaknya tidak mudah dijawab secara scderlana, karena keberlangsungan siaran tclevisi sangat bergartung pada dana yang menojsaug siarannya. Dengan demikian, tampiknya hal itu tidak lepas dari subsidi pemerintah. penjualan air time untuk iklaı, sponsor, dan taktor lain yang ikut berperan serta dalam keberlangsungan sebuah siaran.

Kckl:awatiran masyarakat lextadlap siaran televisi yang karena tidak memihak pada pemirsa dapat dikałak $\bar{c}$.n sudah sangat memprihatinkant. Namun destrikianı, ada juga pihak-pihak tertentu yang sangat menyambut gembira dengan membanjirnya media massa tcrscbul. Menurut Wardimar, sialan lelevisi turut memberikan kontribusi terhatap maraknya kenakalan iemaja. Hal tersebut didukung hasil penelitian balıwa tayangan film televisi untuk anak-anak lebil: banyak menunjukkan adegan-adegan anti sosial bila dibandingkan demgan adegan-adegan prososial. (Kompas, 14 Desember 1993).

Pendapat yang herlawanar dengan pendapat tersebut diatas datang dari pihak TV swasta itt: sendiri, yatilu kurang yakin kalau tayangan televisi mempunyai pengaruh buruk terhadap perilaku masyarakat (baca:anak) (Kumpas, 4 Juli 1996). Hal tersejul merupakan yang wajar sebagai peunbelaan diri. Demikian pula proulapat 
Hadiyanto yang menyatakan bahwa media massa sebenarnya hanya menimbulkan fek yang kecil bahkan tidak menimbulkan elek apapun pada khalayak yang selektif (IIadiyanto, 1996).

\section{Kekuatan Televisi}

Cohen seorang tokch komunikasi terkemuka, dengan penuh bersemangat telah menyalakan, "dalam kebonyakan kendaun, media tidak beruvayn mempengarnhi orang rainai merenlukan bagaimanu untuk berfikir tetapi yang miengajatbkan inlah medic berjaya memperigaruhi pembacanya nntuk meneintukari cpa yang perlu difikirkan."1.

Dalam jangka panjang media massa, kh:ısusnya televisi akar memberi rảngsangan pada an!ak-anak sekolah urtuk menciambakan gaya kehidupan kota yang lebih aktir. Khayyalan yang ditimbulkan dari tayangan televisi di antaranya balnwa anak-3nak berkeinginan monjadi bintang torkena: seperti bintang sepak hola. Fenyanyi yang tenar, dan bintang film terkenal. Dari khayalan akan menimoulkan semangal. bclajar dan bermain yang lebih kreatif jika dibandingkan dengan anak-anak yang tidak tertarik unluk menyaksikan berbigai informasi yang ditayangkan olch media elektronik :elevisi.

Banyaknya stasiun televisi yang bermunculan banu-baru ini di Indonesia, akan menjadi-semakin kcmpetitif untuk menarik pemirsa. Dengaa kondisi ini akan meningkatkan kualitas tayang dan yang merjanjikan kesempatar-kesempatan memperoleh hadiah penissanya. Untuk itı, pengemasan akan sangat beragam. Keunggulan pengemasan berupa tilm akan menumbuhkar: kreatifitas anzk. Karena anak akan berpikir akkliı dari setiap silm yang ditayengkan. Di simping itu, anak-anak tidak akan kehilangan diri hanya karena terlalu banyak menonton televisi (perterson).

\section{Kelemahan (dampak negatif) Televisi}

Seprerti telah dikemukan terdaluulu. segala sesuatu disamoing sisi positif tetap memiliki sisi negatif. Sisi negatif media televisi (dari beberapa btskti) menunjukkan bahwa telcvisi mempengaruhi pandargan anak-anak terhadap realitas sosiai sangat melimpah (A.Door,1982). Salah satu analisis terhadap isi acara tclevisi di Amerika menunjulkkan bahwa teceris. pad̉a umunnya nenvajikan pandangan-pandangan slereotip mengenai peranan litki-laki dan te utama wanita. Sejumlu' kajian menunjukkän bahwa pemissa yang serang menonton televis! sejak umur tiga tahun memiliki jandangan yang stereotip mengenai peraman laki-laki dan terutamai wanita. Sejumlah kajian menunjukkan bahwa pernirsa yang senang menonton televisi sejack urmur t.ga sahun memiltki pandangan yang stereotip tentang peran pria wanita dibandingkika dengan penonlun biasa lainuya (Grecruberg). Hasil Denelitian serupa juga menunjukkin bahwa anak-arlak pereinpuan yarg menonton acara-acara komersial yang menckunk an pentingnya kecantikan fisik cenderung lehilh setuju dengan perryataan bahwa kecantikan isu penting artinya agar populer di kalangau laki-laki. 
Hasil penelitian di Irggris menunjukkan bahwa anak-anak remaja vang orarg, tuanya memiliki televisi justr: Irbih mengkhawatirkan piskeinbangan (liri mereka senciri daripada remaja yang sama letapi yang lidak memiliki pesawa televiși 10ppenheiun dalam Chan, 2005: 46!.

\section{Peluang Televisi}

Med:a le crisi merupakan salah salı sebab mer:gapa anak-anak begitu rritzdab ter peugaruh oleh pesar-pesan dari televisi. kebanyakan anok monganggap apa yang cisaksikan di dalam acara telerisi sebagai suatu reslicas. Anak-anak yang masih targolong pendidikan usia dini) menyamakan scmua acara relevisj fengan kenyatáan. Olelı kisena i[n, kelkasaudn yang timbul disetabkan mereku tjdak sapat memoedakan anlara realita dan klayaian. Senua itu terjad: kànı sesuai pertumbuhan dan tingkat usia yang secisag diulaminya. Semakin bertambah 'mur, anak akar Ircnjadi memahami realiliss telivisi, Dengan sendirinya anak akar: ger:aya bahwa secuatu di lelevisi yanj capat ter'adi di dunia nyata adaliah benat nyata di telcrisi. Merekal percaya bahwa apn yang terlihat di televis: mewakili sestalu yang memang mungkin le-jed. di dunia nyata.

Namun demikian. terdapat ptrubatan-perubahar: da!am pengertian realiles ini. Kepercayaan bahwa duata hiburan diangeap mewakili ralitas :tup nya tidak berubah banyak snteskipun mereka bertambal: banyak pergalastan menonton telcyisi. Contoinya, anak-anak tetap menyamakia dirisyd üengal: tokoh-lokoi fantasi di televisi seperti Baja Ilitâm,
Supermèn, Kapten Tsubasa, dan lain-lẽinnya. Kepercayaan dari dunia yang ditizyangkandi colcvisi membuat anak-anak mudah terpengaruh oich pesan-pesan korncrial yang đisa.npaikan oleh inedia televisi.

Kckhawatiran sebazian vrang tua pada anak-anaknya cerhadap beberapa layangan televisi mexupakan tantangan untuk peryempurman setiap tayangasulya. Oleh karena iru, nara pernasang iklan tems menyempurnakin setias tayangan komersia.nya. Jika kila simak anak-an.ak pada lingkat perdidikan usin dini, mereka lebih gemaz menonton acara-acara televisi. dibandingkan mclakukan aktivitas berangkat sekolan lebih awal, mrmpelrijari pelajada yang relalı diber.kan guru, atau pelajaran yang akaa diajarkan. Anak-anak teb.h halal isi acara-acàra komersiai dan mereka mampu mengingat siogan, buny:, тіаирuil nama-nama merk sualu produk tertentu. Bahkan mercka kerap kali ingin rtemiliki barang-lıa:ang yaug dikiankan di televisi Melihat kondisi ini scbenarrya teleusi menil:kí peluang sebagai alat medi. bciajar bagi anık.

\section{Tantangan ke vepand}

Merabaknya televisi swasta, merur:akan kemüjuan bagi indonesia, ndmun. ritak demikjan bagi kelargan orang lun yang mengr:larapkan anak-amaknya ticak tcrkena husutan-basutan vich acard-acara televis: yang ticiak sesuali dengaia keataan mereka dan yajg, akhirnya juga membera:kan orang h.ta.

Oiel ka:ena itu, pilıak pengrlola medja herdakıya momperliatikan can Jebih mertpons asprasi yang dikemukaka: oleh 
pemirsanya. Namun demikian, para pemirsa tidak dapat memaksa, tetapi hanya sebatas himbauan. Berdatarkan pengalaman empiris, oranglua harus dapat mempengartuhi pengetahuan sosiạl apa pun yang diterima oleh anak-anaknya dari suatu pertunjukan televisi. Orangtua juga dapat memberikan pengerlian-pengertian informasi yang telah diterima oleh anakanaknya agar mereka tidak tellalu termakan oleh iklan komersial yang disajikan pihak televisi, yang akan berpengaruh pada perilaku yang negatil (Muhammad, 2002).

Marshal Mc pada 20 tahun yang lalu telah memperkirakan bahwa media menghasilkan pengaruh sosial dan psikologis pada audience, termasuk hubungan sosial yang khusus, serta bentuk kesadiaran dan cara berpikir yang khusus pula dengan isi yang disampaikan dalam keadaan yang sangat luas (Mci.ulhan, 1964). Arus informasi yang cepat melalui media massa berdampak pada pembuatan peradahan global. Media massa adalah ungkapan yang, mengancung pengertian sebagai proses penyampaian berita melalui sarana telcnis untuk kepentukgan umum dan kclompok sasaran yang besar, dimana penerima dapal merespons secara langsung berita yang telah dilerima. Ungkapan makna meliputi kegiatan dalam jangkauan yang tidak terbatas baik melalui auditif, visual, maupun keduanya.

Beberapa gambaran, di atas merupakan tantangan bagi orangtua, pentidik, pemerintah, dan juga pengelola media massa. Tanpa adanya kerjasama seluruh pihak, scmua itu tidak akan saling menguntungkan.

\section{SIMPULAN DAN SARAN}

\section{Simpulan}

Mengacu pada tujuan penulisan tan permbahasan yang telah dikemukakan terdahulu, dapat disimpulkan bahwa:

a. Pengaruh meria massa khususnya televisi sangat besar terhadap jerkembangan rcmaia dan anak, baik secara fisik maupun psikis;

b. Pengelola media massa lebih berorientasi pada bisnis dari pada dampak yang ditimbulkannya;

c. Media massa sangat efektif untuk menyampaikan dan menyebarkan informasi, schingga efektif pula dalam memanfaatkannya sẹbagai media pendidikan.

\section{Saran}

a. Saran kepada orangtua berkaitan dengan tayangan acara televisi adalah :

- Memperhatikan analk anaknya kelika menonton tclevisi dan memberikan nengertian apa yang telah disaksikan;

- Mencarikan altematif kegiatan yang akan membuat anak tertarik dan senang sckaligus membuat anak melupakan tontonan televisi yang mencandukan.

b. Kepada pengelola media massa (televisi) diharapkan memperhatikan tayangannya dengan lebih memprioritaskan acara yang memberikan dampak positif dan meminimalisasi dampak uegatif terhadap pendidikan audience;

c. Kepada Pemerintah, masyarakat, dan sekolah seharusnya berperan aktif dalam memberikan sumbangan pada media massa tentang pendidikan. 


\section{DAFTAR PUSTAKA}

Achmad, A.S., 1975. Komnnikasi. Ujung l'andang: lembaga Penerbitan Unhas.

A. Thour, 1982. Television and Socialization of the Minority Clitid. New York: Acaremic Press.

Akbar, Reni; Wahadi. Psikologi Perkembingan Anak. Jakarta: P'T Gramedia Wiciasarana Indonesia.

As Sahin, Muhammad bin Abdullah. Agustus 2002. Lima belus Kesalahian Mendidib Anak: Cara Islam Memperfaikinya. Yograkarta: Media Hidlayah.

Ciann, Sam M., 2it05. Kébijakun Pendidikun Éra Oionomi Daerah. Jakarla: Rajawali Pers.

Crow and Crow, 1988. Pengantrut llazu Perdidikur. P'enyadur: Sili Meichatti. MA; Reke Sarrashin, Yogyakarla.

Denis McQuail and Steven Windhal, 1955. Communication Models: lor The Sludy of Mass Communications, Second Fidition; I.rngman, Londion anc New York.

Fisher, B. Abrey, 1978. Teori-teori Komunikasi, Penyunting : Jalaluddin Rahmat; Remaija Rosdakarya, Bandung.

Gudykunst, B. William, 1992. Conmmacating With Strangers, New , York: McGriw-Hill, Inc.

Hancioyo, E, 1997. Murnpertanyakan Peran 'TV Swasiu Sebagai Media Fendidikan, Jurna! Pendidikan P13Kn. No.l/th VILI/1997.

Kresuo, 2003. Multi l'ayer dan Pengarthuya pada Perkermbangan Pribadi A.lak * Majalah Prestasi, Vol.1 No.E, Descmber 2002-Fehruari 2003.

Patricia Monks Greficld, 1989. Pengaruí Telenisi, Video Gume, dan Komputer. Jakarta: Kersint Blanc.
Rugers, Everel' M; 1983. Diffusion of Ir:movations, Third Edition. Lundon; The Free l'ress, Collier Macmilln Publishers.

Sadiman, Arif, dkk, 1993. Medin Pendidikan. Pengembangan pengertian, Pemanfogturne Jakarta: Puschen dan PT Raja Grafindo Persada dalam rangka ECD Project (USAID).

Salomon, 1981. Communication and Edrication, Sccial and l'sychological Interaction. Lenden; Suge Publisation, Buverly Fills.

Schram, Wilhur, 1975. Responsibility in Miss Commurication. New York: Harper and kow.

Senjaya, S. D. uarsil 1994. Xeor Korrunikizsi. Jakarta: Universitas Terbukd.

Setijati, 1986. Definisi Toknologi Pejedidikan, Satnan Tingas Definisi dan Terminologi AECT. Jakarta: Pusar Artar Universitas bekerịa sama dengan CV. Rajawali,

Tirtaraharja: Umar da: La Sula, 2000. Pengurtar Perdidiknn. Jakarta: Rincka Cipta, Depdikbud.

Tonciowidjojs: 1985. Media Massa dan Fendidikan. Yogyaikarta: Kanisius.

Undang-undang Repubiik Iudonesia, Nompr 32 Tahum 2002 Tentang Penyiasau.

Undang-undang Republik Indonesia, Norror 20 Táhun 2003 Tentarig Sistem Pexdid:kan Nasional. 